\title{
Structural and relational support for innovation - formal versus informal knowledge exchange mechanisms in forest-sector learning
}

\author{
by Karen Bayne ${ }^{1, *}$, John Moore ${ }^{2}$ and Simon Fielke ${ }^{3}$
}

\begin{abstract}
In order to drive forest sector productivity, an emphasis has been placed on effectively transferring science knowledge to technical foresters. Having a communications plan and engaging the right stakeholders early can induce a rich learning environment that strengthens context, knowhow and ensures mechanisms are in place for knowledge to be transferred. Formalized structures such as reports and seminars have evolved to improve the science transfer process, but it appears that the key success factor in enhancing uptake and learning may require an environment that encourages relationship building, particularly trust building between parties in developing informal and formal relationships. Informal interactions, though not often acknowledged in business, foster the conditions conducive to good knowledge exchange co-ordination, co-operation and communication. Enhancing conditions in which these three aspects grow can lead to increased social capital, changed paradigms and reduced business costs due to sharing of knowledge and resources. We posit a conceptual framework describing the role of formal and informal knowledge exchange mechanisms and introduce research innovation clusters as a means to promote forest sector engagement and informal relational support for learning.
\end{abstract}

Keywords: knowledge exchange, social capital, forestry, structural, relational, formal mechanisms, informal interaction, innovation cluster, interactive learning

\section{RÉSUMÉ}

Dans le but de stimuler la productivité du secteur forestier, on a cherché à renforcer le transfert efficace des connaissances scientifiques aux techniciens forestiers. Il suffit souvent détablir un bon plan de communication et de mobiliser les bons partenaires dès le départ pour créer un milieu d’apprentissage stimulant qui renforce le contexte, le savoir-faire et assure la mise en place des mécanismes favorisant un transfert efficace des connaissances. Les structures formelles comme les rapports et les conférences ont changé, permettant ainsi d'améliorer le processus de transfert scientifique; mais il semble que le facteur déterminant pour améliorer l'apprentissage repose d’abord sur la mise en place d'un environnement favorable qui stimule le développement des relations entre les individus, particulièrement le renforcement de la confiance entre les parties avec létablissement de relations formelles et informelles. Les interactions informelles, même si elles ne sont pas souvent reconnues au sein des entreprises, créent des conditions propices à un bon partage des connaissances : la coordination, la coopération et la communication. En améliorant les conditions propres à bonifier ces trois volets, il est dès lors possible d'accroître le capital social, de changer les paradigmes et de réduire les coûts pour l’entreprise grâce au partage des connaissances et des ressources. Nous proposons ici un cadre conceptuel qui décrit le rôle des mécanismes formels et informels déchange de connaissances et nous introduisons des grappes d'innovation en recherche comme moyen de favoriser l'implication du secteur forestier et le support relationnel informel à l'apprentissage.

Mots clés : échange de connaissances, capital social, foresterie, mécanismes structuraux, relationnels et formels, interaction informelle, grappes d'innovation, apprentissage interactif

\footnotetext{
${ }^{1}$ Scion, Forestry Road, University of Canterbury, Christchurch New Zealand; * corresponding author: karen.bayne@scionresearch.com ${ }^{2}$ Scion, Rotorua, New Zealand

${ }^{3}$ AgResearch, Hamilton, New Zealand
} 


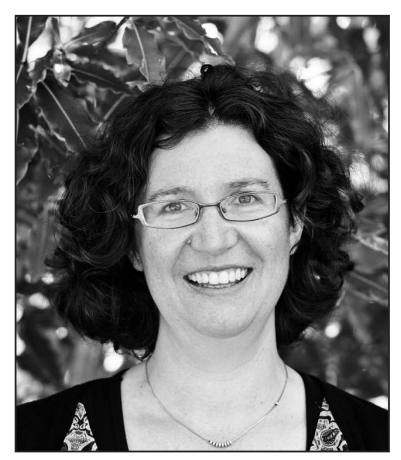

Karen Bayne

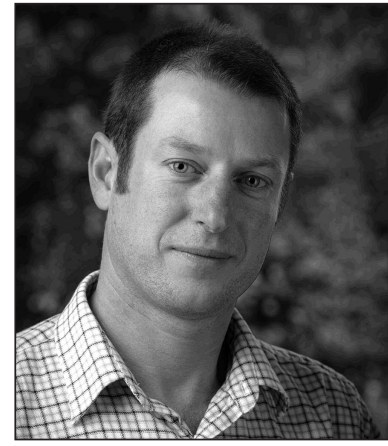

John Moore

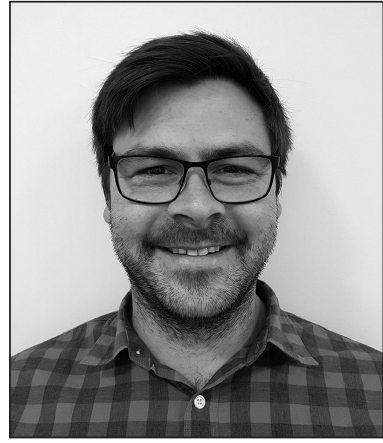

Simon Fielke

effectively, has taken a number of forms over time. Future Forests Research (FFR) was established in 2007 to work in partnership with Scion (New Zealand Forest Research Institute Limited). The prime purpose was to improve the coordination of forest-growing sector research, particularly matching the needs of the industry members who joined up in the consortia with the research activities within Scion. The consortia replaced

\section{Introduction}

New Zealand has 1.7 million hectares of production forest estate, and exports $\$ \mathrm{NZ} 5.0$ billion in forestry exports per annum, accounting for 3\% of GDP, being New Zealand's third largest export sector (MPI 2016). During 2015, New Zealand exported over 17 million $\mathrm{m}^{3}$ of logs, while the volume of logs processed domestically was approximately 13 million cubic meters (FOA 2016). Due to the large amounts of afforestation in the mid-1990s, New Zealand is projected to potentially have annual harvest volumes of approximately 36 million $\mathrm{m}^{3}$ by 2022 . Much of the increase in wood availability will come from small private forest growers (i.e., nonindustrial private forests). The sector companies have traditionally aligned together into a number of separate industry associations for distinct advocacy along the value chain or for increased market access. The forest industry sees research investment as a critical component in realising the potential from the increased harvest through cost reductions and increased added-value processing (FOA 2012, Woodco 2012). To ensure the long-term future of the sector, forest growers also want to improve the economics of forest growing by increasing forest productivity and improving the uniformity and consistency of the trees in these future forests. It is therefore necessary to ensure investment within the science sector manifests into useful knowledge that can be quickly embedded into practical forest management. Knowledge producers and knowledge users require an exchange mechanism that encourages parties to learn and develop knowledge together in a useful and practical manner. The formal and accepted reason and motivation for exchanging knowledge is to take results from research and implement it in practice. The transferred knowledge should be: easy to understand by the receiver; applicable in its context; accessible-both physically, and intellectually (i.e., in layman's language and terminology) and in a knowledge receptacle that the user will find and refer to: relevant - interesting, credible and timely; undertaken by credible researchers (in the eyes of the users); and, cost efficient in terms of time (Becheikh et al. 2010). The knowledge therefore usually requires repackaging in terms of language and format to be useful and accessible to the user in a time-efficient manner. The ability to exchange knowledge more effectively is an important imperative for the sector in order to make targeted investments to gain and optimize the future forests.

Forming closer ties between forest industry and science in New Zealand, such that knowledge can be exchanged more

a former cooperative model, whereby industry members were members of certain cooperative research programs around different forest-growing objectives, e.g., stand growth modelling, site management, plantation management and different species.

In contrast to other New Zealand primary sectors, the forest sector has not had a research levy for funding, relying instead on voluntary co-funding for research from one of the forest sector associations or individual companies. This changed in 2013 when a compulsory levy on harvested wood material was passed into law under the Commodity Levies Act. This levy is administered by the Forest Growers Levy Trust, which now directs funding from monies collected at $\$ N Z$ 0.27/tonne (\$CA 0.26/tonne) in the first year and a maximum levy rate for the six year levy term of \$NZ 0.30/tonne (FOA 2012). Through the Trust, the forest-growing sector has co-funded a new research program Growing Confidence in Forestry's Future (GCFF) which has as one of its objectives "More efficient technology translation and dialogue between researchers and industry" in recognition that "overall levels of innovation will not only be determined by the performance of individual parties, but also by how they interact with each other" (GCFF 2016). The program adopted the principles of co-innovation (Lee et al. 2012, Bitzer and Bijman 2015), which involves participation of multiple stakeholders to understand the problem, its causes and develop workable solutions. To facilitate co-innovation, four innovation clusters were established as a formal interactive mechanism for learning and co-development of knowledge. An innovation cluster includes members from various interest groups (e.g., corporate forestry staff members; government agencies; indigenous (iwi) representatives; research scientists) and others with a background in the specific cluster group focus. The purpose of the innovation clusters is to facilitate technology transfer it focuses on interactive learning and knowledge sharing. The clusters do not have a governance role, and thus program administration and knowledge sharing are kept distinct from each other.

\section{Systems of knowledge transfer}

In a review of existing models which attempt to map knowledge transfer activities, Becheikh et al. (2010) outline four levels of interactivity between knowledge holders and practitioners in the transfer of knowledge, spanning a continuum between researcher-based approaches to a fully interactive model. The first more traditional approach focuses on the 
production of knowledge as a science push, results in a classic linear stage with iterative processes (RDD - research, development, diffusion). The criticisms of this level are the absence of knowledge exchange between actors in different disciplines and fields of expertise, along with an emphasis on university-created knowledge while practically ignoring the user context.

The opposite approach takes need of the user as primary and turns researchers into 'technicians' tasked with responding to these needs. This problem-solving approach has been criticized for placing sole emphasis on a 'user knows best' mind-set, whilst ignoring knowledge and expertise of the research community as having an understanding of what is required. This level also limits communications between user and researcher.

Linkage models ensure formal linkages exist between researcher and user and seek to integrate the concepts of the RDD and problem-solving approaches through a transfer agent. Guena and Muscio (2008) along with Santoro and Gopolakrishnan (2000) highlight the important part played by linkage agents in the transfer process, taking the dyadic transfer process between researchers and users to a triadic process, whereby the linkage agents discern the information and repackage the message so as to be better disseminated and implemented by user groups. While this level has the right intention, the formalized nature of interaction has been criticized for focusing on specific and exclusive mechanisms for engagement between researchers and users.

In contrast, social interaction models depend heavily on the diffusion stage through learning osmosis between researcher and user due to repeated interactions between numerous players involved in the transfer process. This level offers the most dynamic interaction between researcher and user, by placing equivalent importance on the knowledge transferred both ways.

There is an increasing impetus on focussing not on the transfer process amongst research and user alone, but the whole environment or system in which the transfer occurs (Edquist 1997, Rolings 1999). Spielman et al. (2009) state technological change is embedded within a "larger, more complex system of interactions among diverse actors, organizational cultures and practices, learning behaviors and cycles, and rules and norms" (pg 1). This system view recognizes that the development and implementation of 'science-for-impact' is the result of a process of networking, interactive learning and negotiation among a diverse group of people and that innovation is not just about adopting new technologies; it is an adaptive and responsive process.

This then begs the question of how the system in which knowledge exchanges occur in forestry science can enhance networking and build social capital, and how to facilitate the research-user environment to create stronger connectivity that enhances information flows and exchange of knowledge. Our research hypothesis is that innovation clusters are structural catalysts for co-learning that enhance co-operative exchanges of knowledge through developing relational capital. We outline a conceptual framework for enhancing the exchange of knowledge between science and industry, and test the effectiveness of the innovation cluster through a social network analysis.

\section{Theoretical Framework \\ Social capital}

Putnam (2001) described social capital in terms of "connections among individuals - social networks and the norms of reciprocity and trustworthiness that arise from them" (pg19), while Leana and Van Buren (1999) define social capital as "...collective goal orientation and shared trust, which create value by facilitating successful collective action" (pg 538). Social capital therefore consists of both the structural network and relationships built, the degree of shared trust and vision, and the knowledge that is mobilized through the network to create value. Nahapiet and Goshal (1998) explain social capital in three dimensions: A structural dimension that defines connectivity in terms of patterns of interactions and the network properties as a whole; A cognitive dimension that explains the development over time of shared language and behaviours and a common understanding by actors of how the network functions; A relational dimension that looks at the role of the individual within the network in terms of interpersonal relationships developed as a result of ongoing interaction, and where actor appeal and mutual interests along with trust are key relational elements.

Santoro and Gopalakrishnan (2000) state "a firm is better able to absorb knowledge from external sources when it has created porous boundaries, when it scans for technology from a variety of sources, and when it maintains a continuous and consistent interaction with information sources" (pg 300). Such recurring activity is more conducive to building relational channels (Ladd and Ward 2002), as the frequency and depth of human interactions leads to improved understanding of each other's business setting and needs.

Forming closer relations between the sciences and end users, while known to be mutually beneficial, is not often easy nor of high priority for either the research or industrial sectors (Kelli et al. 2013). Literature suggests that the motives for doing so include several factors:

- a joint imperative for the information to solve a pressing need and be quickly implemented (Ladd and Ward 2002, Simpson and Ashworth 2009),

- a requirement for access to important information (either data or results),

- perceived level of risk in technology development,

- or the uncertainty surrounding a known problem (Stock and Tatikonda 2000).

Knowledge transfer increases with a mutual understanding of the problem and leads to congruence around the research priorities and most possible solutions. A knowledge exchange environment where both parties have mutual respect for one another also increases the level of trust and reliability within the system, so that being honest, transparent and respectful in all interactions becomes an expectation amongst members. There is also more likelihood of both parties exploiting the joint social capital (networks built up over time) through informal forums, workshops and meetings to form the basis for more formal collaboration and agreement (Guena and Muscio 2008). Levin and Cross (2004) note that people prefer to learn from others than from documents, and stress the importance of the relationships between parties for social learning to occur, particularly in imparting tacit knowledge. Tacit knowledge deficit can only be bridged through 
dynamic interactions between actors within a supportive learning framework (network/ system) that facilitates tacitexplicit knowledge conversion (Nonaka 1994, Collins and Hitt 2006).

\section{Building structural and relational capital through formal and informal mechanisms}

The current drive of government funding in New Zealand towards greater collaboration between institutes and science fields hopes to both reduce the timeframe in which results can be implemented and to assist industry or public policy, while also creating an environment to promote social learning (MBIE 2015). In order to improve the speed of knowledge exchange, and make research results more relevant and transferable, a number of formal mechanisms have been employed.

A common approach to support user-researcher engagement is through steering or liaison groups, or communities of practice $(\mathrm{CoP})$ to facilitate information exchange between science disciplines and across industries (pan-sector). Communities of Practice are an example of a social interaction model that formalizes and supports stakeholder networks to develop. The existence of these network connections in CoPs build social capital, and facilitate knowledge sharing (Wang and Noe 2010). Improving communications with a broad sector of influential 'fringe' actors in order to challenge the research and user paradigms, as well as informing the research of wider societal issues across a range of perspectives, can drive new research direction (Braund 1995). More formal structures such as industry-research consortia and establishing industry partnered 'centres of excellence' also support knowledge exchange, while focussing research on more tangible user-required outcomes (Fluckiger 2006). Engaging industrial champions to support the research, holding public meetings to discuss findings, as well as proactively engaging local media to report on progress can also assist in knowledge exchange and transfer of best practice to communities (Simpson and Ashworth 2009, Becheikh et al. 2010).

These more formalized engagement structures between users and researchers help to both contextualize the research, and increase knowhow by establishing better sectoral relations between the users and the scientists. Formal engagement involves a level of communication whereby the problem at hand can be given context by the shared understanding of existing knowledge and the environment in which the solution must sit. Knowledge and context are exchanged, with the knowledge transfer providing a facilitation role. An early communication plan and stakeholder analysis is critical to ensure the right level of informal/ formal engagement.

The ability to transfer tacit knowledge depends on close and regular associations that impart positive interpersonal dynamics (Tatikonda and Stock 2003, Collins and Hitt 2006). Because individuals and organizations do not usually have the complete picture and lack resource capability and capacity, they must integrate into networks with those who can contribute what they lack (Spielman et al. 2009). Membership of a network which allows for repeating and enduring relationships to develop increases the potential for knowledge to be exchanged (Inkpen and Tsang 2005). Providing supportive infrastructures, rules and norms that enhance the collective capacity to facilitate knowledge exchange can encourage actors to interact amongst themselves forming networks to share resources and expertise with one another (Kneller 2001).

Yli-Renko et al. (2001) found that external knowledge exchange depended on two key relational aspects: the level of social interaction occurring (frequency of interaction) and the links that members have to external knowledge that other members are not party to (number of network ties). Embedded (informal) relationships form from mutual interpersonal interests that drive reciprocity of information sharing forming a growth in trust (Wang and Noe 2010). Embedded relationships are resilient to changes in structural formation of a network and are moderated by norms in social behaviour (Nahapiet and Goshal 1998). The more informal interactions of scientists with industry can lead to enhanced research performance due to two-way knowledge transfer of ideas and the ability of researchers to adopt different perspectives, driving more innovative research approaches (Guena and Muscio 2008). Also of critical importance is the right mix of people who are contributing to discussions and informing the relationship (Ladd and Ward 2002, Simpson and Ashworth 2009). The effectiveness of creating an innovation network for knowledge exchange depends less on the quality and supply of the information and more on the systemic behaviours and practices which affect social learning and behaviours within organisations and between individuals (Spielman et al. 2009). Individual values, perceptions, previous experiences in knowledge transfer and priorities regarding the knowledge or technology being discussed are also known to impact the degree of transfer (Simpson and Ashworth 2009). Willingness to share knowledge also depends on the competitive value of the information and the perception of how the other party conforms to a norm of open science (Kneller 2001, Häussler et al. 2009, Häussler 2011).

People engage in knowledge sharing when there is a gain in social benefits, with individual attitude and organisational culture strong influencers of the degree of knowledge exchanged (Pacharapha and Ractham 2012). For effective inter-organisational interaction towards collaborative codevelopment, higher levels of organisational interaction skill dimensions (communication, co-ordination and co-operation) are required (Tatikonda and Stock 2003). Important elements of communication include the methods, the frequency and the information being exchanged. Communication is oft touted as a critical element for leaders and managers to possess, however, the media and frequency in which the communication is transferred can help or hinder knowledge exchange (Denise 2015). Co-ordination seeks to improve efficiencies between parties. Co-ordination ensures people know where they are going and their role in the whole scheme - the relationship between their effort and others' critical activities and roles. Important elements of coordination include the degree to which actors work together, the formality of their relationship, and the length of their relationship (Tatikonda and Stock 2003). Denise (2015) states that new ideas are often sparked not by consensus but by disagreement, dissent and even conflict. Co-operation risks being used as a tool to socialize a certain behavioural institution, rather than to enable a safe environment for new views and ideas to emerge. Denise (2015) notes that the opposite of co-operative is competitive, so actors can safely disagree while not competing. Important elements of co-operation include trust, congruence in vision and commitment level, with which there 
becomes safety in which to bring new ideas forward (Tatikonda and Stock 2003).

Rametsteiner and Weiss (2006) show that the benefits of interactions and relationships in place over an extended period are necessary in building the foundations for an effective innovation system in forestry, rather than coming together and building strong ties during the course of a single project. Enhanced trust and respect created and maintained through longer term interaction can lead to being more flexible in negotiating agreements and not impede further collaborative work. Jones et al. (2007) show how efforts made by the Australian fishing sector to increase the level of engagement between science and end users led to mutually rewarding relationships while also allowing sharing of data that reduced costs of gathering and processing research information. Moore et al. (2012) found the function of relationship building in forestry science projects to be critical, and that when science was being created with indigenous peoples in the New Zealand forestry sector, "the additional time spent establishing trust and gaining the active co-operation of bodies and individuals with key roles as intermediaries for intervention design and implementation was found in most cases to be vital investment." (pg 646). Turner et al. (2014) in a study of effective interactions within New Zealand agricultural research and extension systems identified the need for interactions to occur between a variety of actors for enhancing knowledge exchange, and the value of farmers directly interacting with scientists in trials. The authors also found that a key challenge to the effectiveness of these interactions was the lack of linkage extension agency to translate and repackage the information for the receiver.

\section{Conceptual framework}

Formalized structures and emphasis on whole-systems are still required to support the building of relational networks, but the focus should be on building stronger relationships and knowledge-sharing institutions that support and build social capital (Kneller 2001), over the long-term and across a variety of projects rather than solely on the transfer of information. What is clear, however, is that an increased level of interaction between users and researchers is critical, and the nature of engagement may benefit from adopting less formalized structures. We posit that it is the informal structures that exist, and taking steps to grow the nature of the relationship itself rather than a focus on transferring knowledge within an innovation system that leads to an atmosphere for improved knowledge transfer to occur (Fig. 1). Stakeholder analysis and communication plans facilitate the structural and cognitive social capital built from formal relationships in which the context and knowhow of the various parties can be better shared. While this is often the outward manifestation of the relationship, relational social capital allows for tacit knowledge exchange, trust and deeper levels of engagement - elements that are not always outwardly apparent but underpin the ability for knowledge exchange to occur (Pelling et al. 2008). Such informal relationships lead to an organisational culture conducive to and designed/ primed for research knowledge to be implemented in the sector through enhanced co-ordination, communication and co-operation, increasing revenues and enhancing sectoral results. Linkage agents also work to take and repackage information from science, while also providing an important conduit to feedback knowledge and experience from industry.

We suggest that the relationship itself, especially when this is less formalized and when placed within a formal social interaction model, creates very rich environments in which knowledge exchange activities can occur.

\section{Methods}

Eighteen members of the wider forest network were interviewed and the qualitative results analysed to identify the presence of social capital and approaches used to facilitate knowledge exchange. The interview questions included mechanisms that researchers had taken to exchange knowledge with users, degree of interaction with the research programme and the means by which the members were receiving information.

One of the innovation clusters was selected as a case study to quantify the degree of interactions occurring within the network of 31 members. An online survey was developed through SurveyMonkey and distributed to members of the innovation cluster who had come together to investigate the

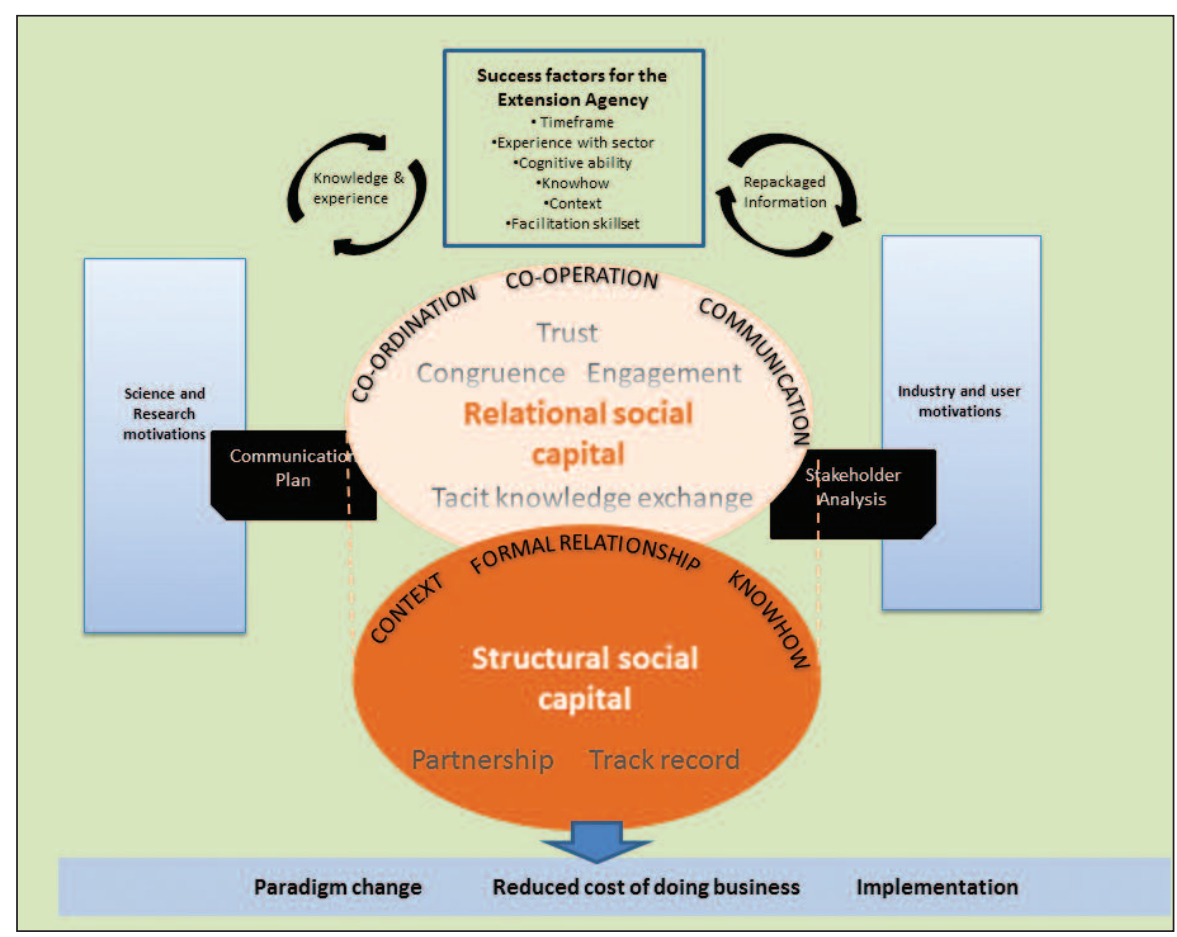

Fig. 1. Conceptual framework of structural and relational social capital activities in facilitating scientific knowledge exchange. 
topic of wood quality and segregation methods. Social network analysis (SNA) provides a means to visually represent interactions between individuals within a network, whereby a matrix of relationships can be transformed into a network map or 'sociogram' (Williams and Hummelbrunner 2011). Two questions were used to determine both a) who within the cluster membership they were interacting with and how often; and b) whether the interactions concerned wood quality and segregation methods. The survey also identified persons outside the formal network that were party to wood quality and segregation knowledge due to informal networks. The degree of interaction was weighted in the following manner for the question "In the previous six months how often have you been in contact with the following people?": a) we talk fairly frequently $($ score $=6)$; b) several contacts have been made (score = 4); c) I know of the person but have not made contact (score $=2)$; and, d) I do not know them $($ score $=0)$. Scores were averaged for the member pairs, for example, where one person said they spoke frequently and the other that there had only been several interactions, a score of 5 would be given for the interaction. The survey also asked whether a conversation around wood quality or segregation methods had been held with the person. This resulted in a simple matrix of 0 and 1 where 1 indicated the topic was discussed between the pair. The survey responses $(n=22)$ were placed into a matrix and entered into network analysis program UCINET to explore relationships, calculate the network centrality and construct a sociogram of network interactivity around the topic of wood quality and segregation methods.

\section{Results}

Early in the Future Forests Research (FFR) program, the tendency of researchers was to communicate the results of their work using the language of science and academics, and via formal written reports. Where the knowledge exchange was directly to end users, this was via a series of seminar presentations. A website was developed for FFR, on which all reports and presentations were made available to industry members for download on a shared portal. However, it became apparent when monitoring web traffic, that the reports and information were only being downloaded relatively few times - in other words, people in industry were not receiving the information or were seeking the information directly from scientists rather than by reading and disseminating research results outlined in reports. Obviously the information deficit model was not an effective means of transferring knowledge, and new approaches emerged in an effort to improve the transfer process. Interviews with respondents revealed that two modes of interaction proved very successful. The first was a series of interactive workshops which included both refreshing of basic knowledge and the integration of new research understanding into practical examples. The second approach was to recruit personnel into the program who were versed in both the science field, but also had some experience in industry, as knowledge brokers or agents. Scientists found that along with a larger uptake and interest in their work, a number of additional benefits occurred from these approaches. Firstly, an ability to learn about sectoral issues and priorities of the end-user; secondly, the opportunity to meet face to face, and 'put a face to the name' of particularly technical foresters within forest companies; and lastly, the ability to increase social capital.

\section{Innovation clusters}

Each cluster includes voluntary members from various interest groups with a background in the specific innovation cluster areas. Typically there is a core of about 10 people, but cluster events may attract up to 30 participants. The clusters operate on an open door philosophy and encourage others interested to join. A key success from interactive learning and knowledge exchange was seen in the field trips following sixmonthly update meetings, where science, government agencies and industry were actively intermingling and communicating together while travelling between stops on the bus trips. Not only was the key science being exchanged, but stronger network ties were able to be developed through interactions that occurred on the day.

\section{Network strength}

The sociogram indicates a strong degree of interaction between participants within this innovation cluster, with all participants having spoken with at least one of the other members at least once or twice over a six-month period. In the case of the network conversations concerning wood quality and segregation methods, this showed a fairly centralized network (Fig. 2), more than twice as large as the estimated cluster network, with five stars (BB, H, K, P, J) holding the network interactions together. Surrounding the central hub are boundary spanners (Q, E, R, F) who are communicating the knowledge out into a wider network of people. More importantly, those who are only loosely connected to the network (by only communicating with one or two other members around the topic) show a very regular communication link with these members with high centrality scores of 4-5. The case study is showing evidence of increasing collaborative behaviours to bring about a prototype segregation tool. Results show that co-operative and co-ordinated behaviours are being encouraged through increasing the opportunities for informal engagement with involvement in field trips and sharing of data and experiences.

\section{Discussion}

When forming the new GCFF program, a concerted effort was made to enhance knowledge exchange through the formation of four innovation clusters to ensure interactive learning and allow for the establishment of new relational linkages to be created. The innovation clusters served a number of purposes. While the main purpose was to provide a forum to develop a deeper understanding of key issues, review science advancements and discuss the practical implementation of these, the clusters also facilitated the building of trust and enhanced co-operative developments by facilitating co-innovation and technology transfer and enabled interactive learning by actively engaging with stakeholders. A range of structured activities as formalized transfer mechanisms were established such as regular discussion meetings, seminars, and workshops, along with collaborative industry-led research activity. An interesting insight was that the workshops were supported by industry not only for the knowledge exchanges made in terms of science advances, but also for the 


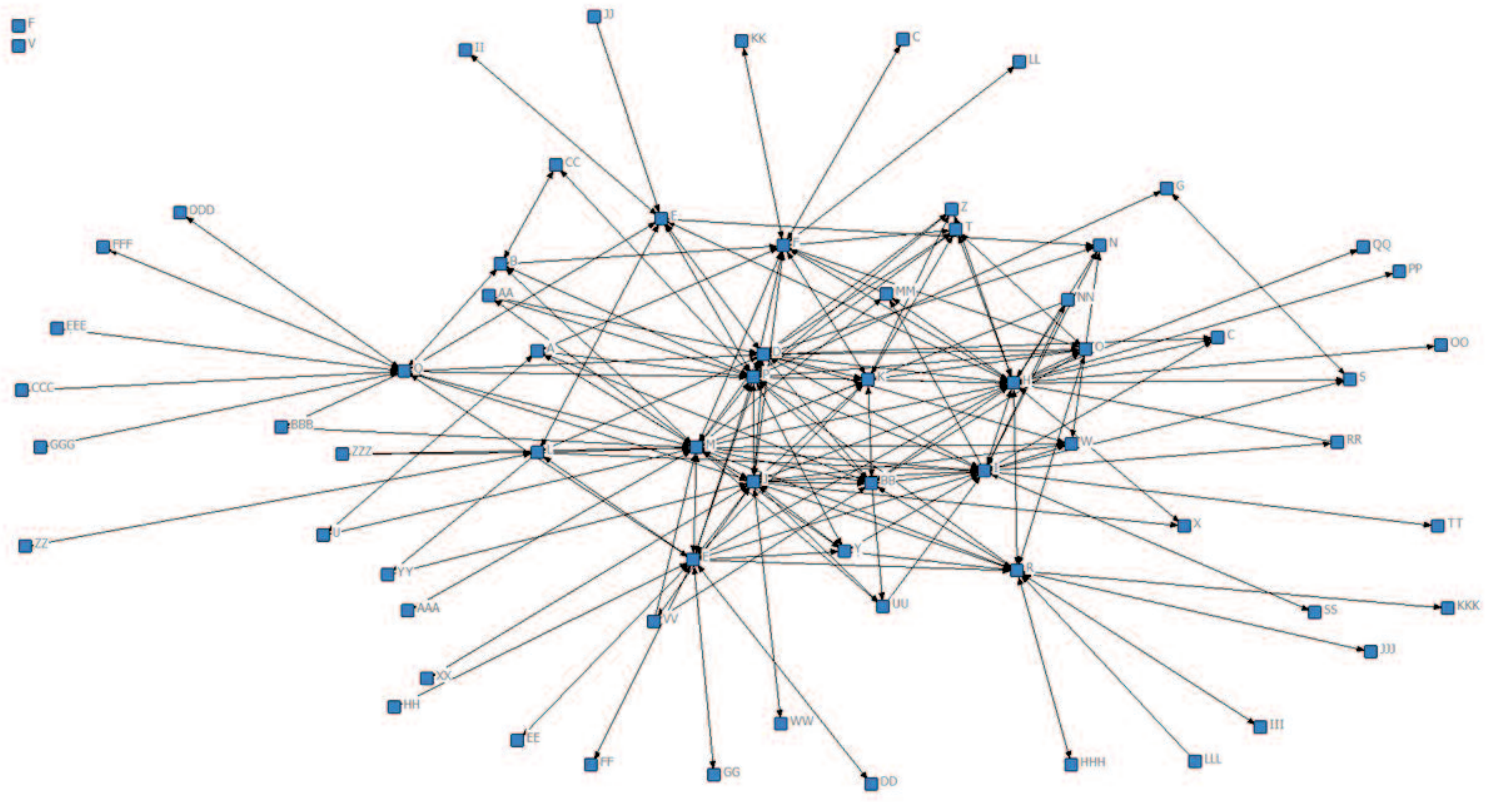

Fig.2. Sociogram showing degree of interaction between innovation cluster members and other participants concerning wood quality segregation tools. Each square represents a single actor in the network, with lines showing connections. The names of these actors have been removed for privacy reasons.

networking opportunities with other companies in the sector and the ability to meet informally and identify others 'of like mind' as potential collaborative partners. In some cases, the main reason participants noted for attending the workshop sessions was for the informal networking rather than the science knowledge dissemination, as the informal discussions were seen as a better method of enhancing business linkages. Those interviewed also described the continuation of business linkages formed from workshops and meetings through regular phone and email discussions as a critical means of strengthening the formal network, stating that it was through getting to know each other that trust was formed. The innovation cluster enables actors within the forestry sector with an interest in developing wood quality segregation tools to come together using active learning processes to address the systematic requirements of the research program.

Innovation clusters can develop organically from within existing industry connections but a cluster group requires a focus and goal to progress and accelerate knowledge exchange amongst the group. Learning occurs through engagement opportunities and innovation clusters can provide the formalized structure by which there is genuine engagement in a science program. Through interactive discussion and 'learning by doing' via demonstrations and field visits, participants can begin to build long-lasting social capital.

The importance of the linkage agent and the ability of scientists to be able to confer the knowledge in an appropriate manner to facilitate learning is a critical component to ensuring the success of an innovation cluster.

Sociograms can reveal the presence and identity of system bottlenecks (where information must pass to get from one part of a system to another); brokers, who span the boundary of the system with those not closely linked to other members; and central hub members or stars, who have the best access to information flows throughout the network and are strongly connected to other members. SNA was performed with one of the innovation cluster groups whose members were exploring the topic of improved processing through segregating on wood quality characteristics. The SNA mapped the current connections emanating from the cluster group among growers, processors and others in the forestry supply chain. Having strong networks is one thing; however, the purpose of the cluster and wider network is to facilitate conversations that lead to innovative timber segregation tools being co-developed. This obviously cannot occur if no one is discussing the segregation issue at hand through the interactions, or the conversations are either being kept within a 'tight few', or failing to include significant network players (especially key enablers or influencers). Correlations between the interactivity and the conversations concerning the cluster's purpose in terms of degree of centrality, indicate that some people, while wellconnected, are having only few conversations about segregation. The stars are therefore critical to the leadership, communication and understanding across the network in relation to 
wood quality and segregation, and have the strongest levels of interaction with others in the network, indicating a high level of consistency in advanced science knowledge on this topic throughout the network. This indicates people are using their established existing networks to discuss the cluster group issues, rather than forming a new social network to address issues surfacing within the cluster meeting discussions. Knowledge should be exchanged more quickly and take less time to be incorporated into practice as conversations will occur naturally, although there may be a tendency to not look outside the obvious established network for information or dissemination of data. Those within the network who are stars in the central hub in particular will likely have developed the common language and context required to ensure effective exchange of knowledge-over time they will have learnt what types of knowledge different members require and may have developed specific translator skills to exchange information. It takes time to develop both sufficient credibility for effective engagement and cognitive understanding of the network structure, however these skills are usually only able to be honed in an environment of trust and openness, requiring a system that encourages greater levels of informal interaction.

There is scope to expand the conversations beyond the "obvious" interactions to fringe actors within the network and to use boundary spanners or brokers to facilitate conversations between the fringes and the stars. The network could be improved by encouraging these folks to discuss the issue to a greater level within their networks or alternatively, for others in the network (particularly the influencers and stars) to initiate conversations with these people, such that it becomes more pertinent topic of conversation when discussing other matters with colleagues and peers.

\section{Conclusion}

The conceptual framework was used to explain the presence of structural and relational capital within the New Zealand forest sector through a case study of an innovation cluster network. Our experience in providing a formal mechanism (innovation cluster) in which social capital can be built, has shown the importance of allowing informal engagement to flourish in order to achieve an environment in which innovation can occur and drive forest sector productivity. The exchange of knowledge, including tacit knowledge, depends on strengthened network ties in which the stars and boundary spanners within the system are critical. The speed of knowledge exchange can be enhanced due to relational dimensions of social capital, which increase trust, reciprocity of knowledge sharing, and a more direct linkage to influencers and enablers of sector change.

\section{Acknowledgements}

The authors wish to thank Mr. Graham Coker and Dr. Peter Edwards (Scion) and Dr. Barbara King (University of Melbourne) for their helpful suggestions and assistance in reviewing the paper. We also thank the innovation cluster members we interviewed and surveyed as part of this work for their time and insights. This research was funded by the New Zealand Government research program contract Primary Innovation CONT-30071-BITR-AGR, administered by the Ministry of Business, Innovation and Employment through a Biological Industries Targeted Research Grant.

\section{References}

Becheikh, N. Z., Siliha., O. Idrissi, Y. Castanguay and R. Landry. 2010 How to improve knowledge transfer strategies and practices in education? Answers from a systematic literature review. Res. High. Educ. Available Online: http://www.aabri.com/manuscripts/ 09418.pdf

Bitzer, V. and J. Bijman. 2015. From innovation to co-innovation? An exploration of African agrifood chains. Br. Food J. 117(8): 2182-2199.

Braund, D. 1995 Changing paradigms in animal agriculture: The role of academia and industry in technology transfer. J. Anim. Sci. 73(10): 3173-3177.

Collins, J. and M. Hitt. 2006 Leveraging tacit knowledge in alliances: The importance of using relational capabilities to build and leverage relational capital. J. Eng. Technol. Manage. 23(3): 147-167

Denise, L. 2015. Collaboration vs. C-Three (Cooperation, Coordination, and Communication). Innovating 7(3): 1-4

Edquist, C. 1997 Systems of Innovation - Technologies, Institutions and Organizations, Pinter, London, U.K.

Fluckiger, S. 2006 Industry's challenge to Academia: Changing the bench to bedside paradigm. Exp. Biol. Med. (London, U. K.) 231(7): 1257-1261.

FOA 2012. New Zealand Forestry Science \& Innovation Plan. January 2012. Wellington : Forest Owners' Association. [Online] available at: http://www.nzfoa.org.nz/resources/file-libraries-resources/ research-science-technology/480-nz-forestry-science-innovationplan-january-2012/file

FOA 2016. Exports [Online] available at: http://www.nzfoa. org.nz/plantation-forestry/exports

GCFF, 2016. The Programme. Available at https:/gcff.nz/theprogramme/ [Accessed 10 June 2016]

Guena, A. and A. Muscio. 2008. The Governance of University knowledge transfer. SPRU Electronic Working Paper Series. University of Sussex, Brighton, UK. Paper No 173: 1-29.

Häussler, C. 2011. Information-sharing in academia and the industry: A comparative study. Res. Policy 40(1): 105-122.

Häussler, C ., J. Lin and J. Thursby. 2009. Specific and General Information Sharing Among Academic Scientists, NBER Working Papers 15315, National Bureau of Economic Research, Inc.

Inkpen, A.C. and E.W.K. Tsang. 2005. Social capital, networks, and knowledge transfer. Acad. Manage. Rev. 30 (1): 146-165

Jones, A., S.J Slade, A.J. Williams, B.D Mapstone and K.J Kane. 2007. Pitfalls and benefits of involving industry in fisheries research: A case study of the live reef fish industry in Queensland, Australia. Ocean Coastal Manage. 50 (5-6): 428-442.

Kelli, A., T. Mets, L. Jonsson, H. Pisuke and R. Adamsoo. 2013. The changing approach in Academia-Industry collaboration: From profit orientation to innovation support. Trames. 17 (67/62) 3: 215-241.

Kneller, R. 2001. Technology transfer: A review for biomedical researchers. Clin.Cancer Res. 7(4): 761-774.

Ladd, A. and M. Ward. 2002. An investigation of environmental factors influencing knowledge transfer. J. Knowledge Manage. Prac. 1-12. Available from: http://www.tlainc.com/articl38.htm [Accessed 10 June 2016]

Leana, C and H. Van Buren. 1999, Organisational Social Capital and Employment Practices, Acad. Manage. Rev. 24 (3): 538-55.

Lee, S. M., D.L Olson and S. Trimi. 2012. Co-innovation: Convergenomics, collaboration, and co-creation for organizational values. Manage. Dec. 50 (5): 817-831.

Levin, D.Z. and R. Cross. 2004. The strength of weak ties you can trust: The mediating roles of trust in effective knowledge transfer. Manage. Sci. 50 (11): 1477-1490.

Moore, D., K.M Bayne and T.D. Barnard. (2012). Science as a service: Understanding successful knowledge transfer in a New Zealand research institute. Work 41(1): 642-647. http://dx.doi.org/10.3233/ WOR-2012-1009-642 
MBIE (2015). National Statement of Science Investment: 20152025. Ministry of Business, Innovation and Employment, Wellington. Available from http://www.mbie.govt.nz/info-services/scienceinnovation/pdf-library/NSSI\%20Final\%20Document\%202015.pdf [Accessed 10 June 2016]

MPI (2016). News and Resources. Forestry [online] available at: https://mpi.govt.nz/news-and-resources/open-data-and-forecasting/forestry/ [Accessed 10 June 2016]

Nahapiet, J. and S. Ghoshal. 1998 Social capital, intellectual capital, and the organizational advantage, Acad. Manage. Rev. 23 (2): 242-266.

Nonaka, I. 1994. Dynamic theory of organizational knowledge creation. Organ. Sci. 5 (1):14-37.

Pacharapha, T. and V. Ractham. 2012 Knowledge acquisition: The roles of perceived value of knowledge content and source. J. Knowl. Manage. 16 (5): 724-739 doi 10.1108/13673271211262772

Pelling, M., C. High., J. Dearing and D. Smith. 2008. Shadow spaces for social learning: A relational understanding of adaptive capacity to climate change within organisations. Environ. Plann. A 40 (4): 867-884. doi: 10.1068/a39148

Putnam, R. 2001 Bowling Alone: The Collapse and Revival of American Community. Simon and Schuster. p. 19. ISBN 978-07432-0304-3.

Rametsteiner, E. and G. Weiss. 2006. Innovation and innovation policy in forestry: Linking innovation process with systems models. Forest Policy Econ. 8 (7): 691-703

Roling, N. 2009. Pathways for impact: Scientists' different perspectives on agricultural innovation. Int. J. Agric. Sustain. 7 (2): 83-94

Santoro, M. and S. Gopalakrishnan. (2000). The institutionalisation of knowledge transfer activities within industry-university collaborative ventures. J. Eng. Technol. Manag. 17(3-4): 299-319.
Simpson, P. and P. Ashworth. 2009. ZeroGen new generation power - a framework for engaging stakeholders. Energy Procedia 1(1): 4697-4705.

Spielman, D., E. Boir and K. Davis. 2009. The art and science of innovation systems inquiry: applications to Sub-Saharan African agriculture. Technol. Soc. 31 :399-405 doi:10.1016/j.techsoc. 2009.10.004

Stock, G. and M. Tatikonda. 2000. A typology of project-level technology transfer processes. J. Oper. Manage. 18(6): 719-737.

Tatikonda, M. and G. Stock. 2003. Product technology transfer in the upstream supply chain. J. Prod. Innov. Manage. 20(6): 444-467. Turner, J., K. Rijswijk, T. Williams, T. Barnard, and L. Klerkx. 2014. Challenges to effective interaction in the New Zealand agricultural research and extension system: An innovation systems analysis. Exten. Farming Syst. J. 9 (1): 89-98

Wang, S. and R. Noe. 2010 Knowledge sharing: A review and directions for future research. Human Res. Manage. Rev. 20(2): 115-131 http://dx.doi.org/10.1016/j.hrmr.2009.10.001

Woodco. 2012. New Zealand Forest and Wood Products Industry Strategic Action Plan. Available at: http://woodco.org.nz/images/ stories/pdfs/ForestWood_Strategic_Action_Plan.pdf [Accessed 10 June 2016]

Williams, B. and R. Hummelbrunner. 2011. Systems concepts in action: A practitioner's toolkit. Stanford Press, California. 319 p.

Yli-Renko, H., E. Autio and H. Sapienza. 2001. Social capital, knowledge acquisition, and knowledge exploitation in young technology-based firms. Strat. Manage. J. 22: 587-613.doi:10.1002/ smj.183 